\section{Cureus}

\title{
Recent Advances and Therapeutic Options in Lambert-Eaton Myasthenic Syndrome
}

\author{
Arsalan Anwar ${ }^{1}$, Sidra Saleem ${ }^{2}$, Mirza Fawad Ahmed ${ }^{3}$, Sara Ashraf ${ }^{4}$, Sameen Ashraf ${ }^{5}$ \\ 1. Neurology, University Hospitals Cleveland Medical Center, Cleveland, USA 2. Neurology, University of \\ Toledo, Toledo, USA 3. Internal Medicine, Lahore Medical and Dental College, Lahore, PAK 4. Internal \\ Medicine, Sharif Medical and Dental College, Lahore, PAK 5. Internal Medicine, Dow Medical College and \\ Civil Hospital Karachi, Karachi, PAK
}

$\square$ Corresponding author: Arsalan Anwar, drarsalananwar@gmail.com

Disclosures can be found in Additional Information at the end of the article

\section{Abstract}

Lambert-Eaton Myasthenic Syndrome (LEMS) is an autoimmune-mediated neurological disorder that manifests as muscle fatigue, diminished tendon reflexes, with symptoms of cholinergic overactivity. It can be associated with certain neoplastic conditions, the most common being small cell lung carcinoma (SCLC). The basic pathophysiology involved is antibody-mediated targeting of voltage-gated calcium channels (VGCC), which decreases the release of acetylcholine in the synaptic junction. Multiple treatment options have been introduced in the past and, recently, a new drug, amifampridine, has been approved by the Food and Drug Administration (FDA) for the treatment of weakness associated with these patients. We summarize this newly introduced drug with a brief description of other treatment options available.

Categories: Neurology, Internal Medicine

Keywords: lambert - eaton myasthenic syndrome, therapy, prognosis, pathophysiology

\section{Introduction And Background}

A revolutionary article was published in the Journal of the American Medical Association (JAMA) in 1956, briefing about the syndrome with the neuromuscular transmission defect discovered by Eaton and Lambert, which was the basis for the coined name of the disease, Lambert-Eaton Myasthenic Syndrome (LEMS) [1]. LEMS is an autoimmune disorder of the neuromuscular junction caused by antibodies produced against the voltage-gated calcium channels (VGCC) on the presynaptic nerve terminals, thus inhibiting the release of the neurotransmitter acetylcholine (ACh) [2]. The clinical manifestation of the disease is muscle fatigue, which principally affects the proximal parts of extremities. The tendon reflexes are absent or diminished in these patients [3]. LEMS is also accompanied by symptoms that are representative of cholinergic dysautonomias such as decreased salivation, sweating, constipation, and impotence. Oculobulbar involvement, presenting as ptosis or diplopia, is seen more in myasthenia gravis (MG) as compared to LEMS [4]. LEMS is classified as paraneoplastic or idiopathic. A large fraction of LEMS cases have an underlying tumor, primarily small cell lung carcinoma (SCLC). The occurrence of MG is 46 times more than LEMS. LEMS has a male predominance in $60 \%-75 \%$ of patients in contrast to MG where most cases are seen in females. The age of onset in patients with non-paraneoplastic LEMS is the same as in MG, which is usually around 35 years of age. In contradiction, paraneoplastic LEMS peaks at around 58 years. Seventy-three percent of SCLC individuals are also confirmed as having LEMS $[5]$. 


\section{Review}

\section{Etiology}

LEMS is elicited by auto-antibodies that form against the VGCC present in the cell membrane of neurons. These anti-VGCC antibodies are highly sensitive, as they can be detected in $85 \%$ of affected individuals. Most frequently, the VGCC autoantibodies detected in such patients' serum are formed against the alpha1 subunit of presynaptic receptors and bind with the alpha1 subunit or, rarely, the beta3 subunit. Therefore, various parts of the presynaptic VGCC complex are potential targets for antibodies [6-7].

It is also reported that non-paraneoplastic LEMS patients are associated with underlying immune-mediated diseases. Wirtz et al. concluded that $27 \%$ of non-paraneoplastic LEMS patients and $11 \%$ of paraneoplastic LEMS had underlying immune disorders, including type 1 diabetes and thyroid disease [8]. Titulaer et al. showed, in a small case series of paraneoplastic LEMS patients, a persistent affiliation with human leukocyte antigen (HLA)-B8 in class 1 and HLA-DQ2 and HLA-DR3 in class 11. Around 65\% of non-paraneoplastic LEMS patients were found to be HLA-B8 positive, and 50\% were HLA-A1 positive while the same frequency existed for HLA-DQ2 and HLA-DR3 [9].

In both the paraneoplastic and idiopathic forms of LEMS, clinical symptoms are due to an antibody-mediated reduction of VGCC in the presynaptic terminal of the neuromuscular junction (NMJ). Reduction in VGCC leads to a decrease in Ca2+ influx, which is required for presynaptic vesicle fusion and neurotransmitter release. This neurotransmitter, acetylcholine (Ach), is required for postsynaptic muscle contraction. Although in LEMS, NMJ compensates for VGCC, but this compensation is not sufficient to restore the normal amount of neurotransmitter release and thus muscle contraction [10].

\section{Diagnosis}

LEMS is first suspected based on clinical signs and symptoms showing the classic triad of proximal muscle weakness, decreased tendon reflexes, and autonomic dysfunction [11]. The clinical findings need to be confirmed by different electrophysiological studies, such as electromyography (EMG) and nerve conduction studies (NCS). Motor and sensory nerve conduction studies show that the compound muscle action potential (CMAP) amplitude of resting muscle in LEMS patients is lower than the standard [12]. The choice of test for diagnosis is repetitive nerve stimulation (RNS) where a low-frequency stimulation of $2-5 \mathrm{~Hz}$ shows a decremental response [8]. A reproducible increase in the CMAP amplitude of $100 \%$ or more, with a high-frequency stimulation of $50 \mathrm{~Hz}$ (post-activation stimulation), or after vigorous stimulation of muscle for 10s (post-exercise stimulation) confirms LEMS [13]. Needle EMG shows erratic changes in motor unit action potential as low and short during the voluntary action potential. This can be followed by single-fiber EMG measurements of jitter. The increase in jittering shows transmission-blocking and corresponds with the severity of the disease [14].

A blood test to detect antibodies against VGCC on the nerve side of the NMJ is present in $85 \%$ $90 \%$ of patients with LEMS [2]. The test alone is not confirmatory of the disease, but it is a sensitive test along with clinical signs. The presence of antibodies to VGCC does not correspond with the severity of the disease, but as the patient is started on immunosuppressive therapy, sensitivity to this test is decreased, as antibody production is reduced, and is effective when performed before the start of treatment [13]. VGCC has two types of antibodies targeted towards them and $\mathrm{P} / \mathrm{Q}$ type antibodies are most commonly seen in LEMS but a very small percentage has also shown type-N antibodies with an increased incidence of SCLC in them [15].

\section{Treatment options}


There are multiple treatment options available for the symptomatic treatment of LEMS and the most effective ones are those that increase acetylcholine release from the presynaptic membranes. If LEMS and malignancy are present, the primary concern is cancer therapy as successful tumor therapy in LEMS patients also helps reduce the symptoms of LEMS [16-17]. The treatment option can be characterized depending upon its therapeutic impact on improving weakness in patients.

In patients with mild weakness, regular follow-up is advised and patients are treated if any concomitant malignancy is present [18]. The following are some drug options explained along with recent advances to treat moderate to severe and refractory weakness.

\section{Recent advancement}

\section{Amifampridine}

The main therapeutic focus in LEMS is to improve neuromuscular transmission. Many symptomatic treatments have been experimented in the past few decades, including pyridostigmine, guanidine, 4-aminopyridine, and 3,4-Diaminopyridine(3,4-DAP), with the last one proving to be the most efficacious [19]. 3,4-DAP binds to the VGCC, causing them to remain open for a longer duration by blocking presynaptic potassium channels. These potassium channels prolong the depolarization at the nerve endings, thus increasing the calcium influx with the subsequent release of ACh from motor nerve terminals improving LEMS-related muscle weakness [20].

Many trials were conducted in the recent past that have successfully shown the drug's efficacy and improvement in the Quantitative Myasthenia Gravis (QMG) score. The side effects of the normal therapeutic range are mild, including perioral and extremity paresthesias, nausea, vomiting, and elevated liver enzymes. The side effects of more severity, such as seizures, have a low risk of occurrence because of the drugs low penetration in the CNS, but as it is dosedependent, it can occur at doses greater than $100 \mathrm{mg}$ per day. 3,4-DAP was first approved in Europe in December 2009 and later, in 2010, it was recommended as a first-line symptomatic treatment for LEMS [21]. Amifampridine phosphate is the salt form of the 3-4-DAP base and it is more stable [22]. The starting dose of amifampridine prescribed for adults is $15-30 \mathrm{mg}$ orally three times a day. The maximum approved daily dose is $80 \mathrm{mg}$ a day. The US Foods and Drug Administration (FDA) approved the use of amifampridine in November 2018 for adults (Firdapse) [23].

Table 1 summarizes the trials showing the efficacy of amifampridine in patients suffering from LEMS. 


\section{Cureus}

\section{Year/Study Description (methodology)}

Wirtz et al.

[19], 2008,

Netherlands.

\section{Sanders et}

al. [24],

1999, North

Carolina,

USA.

\section{McEvoy et}

al. [25]

1989 ,

Minnesota,

USA.

Oh SJ et al.

[26], 2016,

Alabama,

USA.

Oh SJ et al.

[27], 2009,

Alabama,

USA.

Keogh et al.

[28], 2011.

Tyne, UK.

Sanders et

al. [29],

2018, North

Carolina,

USA. placebo on the next 3 days. years in part 4. RNS, and SFEMG.
26 patients were divided into two groups, one group with 12 patients was taking 3-4-DAP and another group was on placebo. QMG score and secondarily CMAP amplitude was measured in both groups.

12 patients were given open-label 3,4-DAP orally $25 \mathrm{mg}$ four times a day for the first 8 days and later assigned randomly for either drug or

A 'withdrawal trial' was carried out in 4 parts. In part 1 optimal tolerated dose of 3,4-DAP was given which was then tapered off and replaced with placebo, in randomly selected patients, in part 2. In part 3 the established dosage was then administered for seven additional days with some patients taking part in safety assessment up to two

7 patients, randomly assigned placebo and DAP, had baseline measurements of subjective scores and muscle strength, QMG score,

2 placebo-controlled trials consisting of 38 patients consuming 3,4DAP. A third crossover trial in 9 patients receiving IV immunoglobulins. Primary efficacy end-point is enhanced QMG score and secondary being improved CMAP amplitude.

32 patients were randomly selected and the dose of either 3,4-DAP or placebo for more than 3 months was given. $>30 \%$ deterioration in Triple timed Up-and-Go (3TUG) and changes in self-assessment of LEMS-related weakness was noted.

\section{Result}

Combination therapy with 3-4DAP and pyridostigmine was not statistically significant than 3-4DAP alone.

The QMG score and secondary CAMP amplitude showed improvement with minimum side effects in the treatment group.

Neurologic disability scores decreased with increased muscle strength and CMAP amplitude. Side effect such as seizure is dose-dependent.

Primary efficacy, QMG, and SGI scores were markedly improved in Day 8 and 14 of the studies, hence proving the efficacy of Amifampridine use.

DAP changes the difference in values from baseline was statistically significant, unlike placebo change.

Significant improvement in both QMG score and CMAP amplitude in 2 trials of 3,4-DAP. IV immunoglobulins, however, did not show significant improvement in CMAP amplitude.

Participants receiving 3,4-DAP did not have $>30 \%$ deterioration in (3TUG) with positive changes in W-SAS, contrary to a placebo group.

\section{TABLE 1: Clinical trials (amifampridine)}

\section{Other}

Guanidine 
Guanidine was approved as the first-line agent in the treatment of LEMS but because of multiple side effects, its usage has been limited [30]. Apparently, guanidine functions by increasing the release of acetylcholine after a nerve impulse. It can also slow down muscle cell membrane depolarization and repolarization rates [31]. If amifampridine is not available or tolerated, then guanidine can be advised with or without pyridostigmine in low doses (1000 $\mathrm{mg}$ /day) because of its toxicity profile. It is associated with multiple side effects, such as renal toxicity, and gastrointestinal disturbances such as anorexia, diarrhea, gastric irritation, and bone marrow suppression [30].

\section{Pyridostigmine}

Pyridostigmine has been advised in the treatment of moderate to severe weakness along with guanidine. It has better tolerance as compared to the rest of the acetylcholinesterase inhibitors. The mechanism of action of pyridostigmine is by increasing the concentration of acetylcholine in the synaptic clefts by the reversible inhibition of cholinesterase activity to improve the parasympathetic tone [30]. The dose recommended for treating LEMS is wide and ranges from $30 \mathrm{mg}$ to $180 \mathrm{mg}$. The dosing intervals depends upon the side effects and clinical response. The side effects associated with pyridostigmine are mild such as nausea, abdominal cramping, and diarrhea [28].

In patients suffering from refractory weakness and not responding to acetylcholinesterase inhibitors, immunomodulators are used to target the immune system, as it has been central in showing resistance to the treatment.

The following options can also be used in the treatment of LEMS.

\section{Intravenous Immune Globulin}

Intravenous immune globulin (IVIG) is considered a first-line treatment option to treat the refractory pattern of weakness seen in patients with LEMS. The mechanism of action of IVIG is unknown, but it is suspected that it works by neutralizing pathogenic autoantibodies and by regulating autoreactive B cells [32]. The total dose of $2 \mathrm{~g} / \mathrm{kg}$ is effective for the course of two to five days; maintenance therapy for four to 12 weeks with repeat infusion has also been beneficial for patients who initially responded to IVIG treatment. It takes two to four weeks for IVIG to improve weakness, followed by recurrent weakness in the next few weeks [33]. The complications and side effects associated with IVIG are minor and include laboratory changes, rash, headache, and, rarely, deep venous thrombosis [34].

Table 2 summarizes the immunosuppressive agents used in patients suffering from LEMS. 


\section{Cureus}

\begin{tabular}{|c|c|c|c|}
\hline Name & Mechanism of Action & Dosage & Side Effects \\
\hline $\begin{array}{l}\text { Prednisone } \\
\text { [35]. }\end{array}$ & $\begin{array}{l}\text { Decreases migration of polymorphous- } \\
\text { lymphocytes, reducing the activity of the } \\
\text { lymphatic system to suppress the } \\
\text { immune system. Slowing down vascular } \\
\text { permeability to reduce inflammation. }\end{array}$ & $\begin{array}{l}\text { The starting dose is } 1 \mathrm{mg} / \mathrm{kg} \text { to } \\
1.5 \mathrm{mg} / \mathrm{kg} \text { every other day. } \\
\text { After improvement, the dose } \\
\text { can be tapered based on the } \\
\text { clinical situation of the patient. }\end{array}$ & $\begin{array}{l}\text { Hypotension, } \\
\text { osteoporosis, infection, } \\
\text { shock. }\end{array}$ \\
\hline $\begin{array}{l}\text { Azathıoprine } \\
\text { [36]. }\end{array}$ & $\begin{array}{l}\text { Halting DNA replication and blocking } \\
\text { purine synthesis. The 6-thioguanine } \\
\text { nucleotide is involved in causing } \\
\text { immunosuppressive and toxic effects. }\end{array}$ & $\begin{array}{l}\text { Starting trom } 50 \mathrm{mg} \text { twice a } \\
\text { day and going up to a total } \\
\text { dose of } 2 \text { to } 3 \mathrm{mg} / \mathrm{kg} / \text { day. }\end{array}$ & $\begin{array}{l}\text { Gastrointestinal side } \\
\text { effects such as nausea, } \\
\text { vomiting, flu-like illness, } \\
\text { malaise, hepatotoxicity. }\end{array}$ \\
\hline $\begin{array}{l}\text { Mycophenolate } \\
\text { [36] }\end{array}$ & $\begin{array}{l}\text { Decrease proliferation of } \mathrm{B} \text { and } \mathrm{T} \\
\text { lymphocytes by halting de-novo guanine } \\
\text { synthesis. }\end{array}$ & 1000 mg BID & $\begin{array}{l}\text { Nausea, diarrhea, and } \\
\text { occasionally leukopenia. }\end{array}$ \\
\hline $\begin{array}{l}\text { Cyclosporine } \\
\text { [37]. }\end{array}$ & $\begin{array}{l}\text { It works by Inhıbitıng and decreasıng the } \\
\text { production of interleukin II and resulting } \\
\text { in decreased activity of T lymphocytes. }\end{array}$ & $\begin{array}{l}\text { Starting from } 100 \mathrm{mg} \text { divided } \\
\text { into two doses and increased } \\
\text { up to } 3-6 \mathrm{mg} / \mathrm{kg} / \text { day. Given with } \\
\text { pyridostigmine if it does not } \\
\text { improve symptoms alone. }\end{array}$ & $\begin{array}{l}\text { Decrease GFR, renal } \\
\text { toxicity, hypertension, } \\
\text { tremor, gingival } \\
\text { hyperplasia, nausea, } \\
\text { gingival hyperplasia, and } \\
\text { flu-like symptoms. }\end{array}$ \\
\hline
\end{tabular}

\section{TABLE 2: Immunosuppressive agents}

DNA: deoxyribonucleic acid; GFR: glomerular filtration rate

\section{Rituximab}

It is recommended for use when other immunosuppressive agents fail to give sufficient clinical response. Trials [38-39] conducted retrospectively showed the efficacy of these substances in patients suffering from LEMS. It is a monoclonal antibody that works by binding to the CD20 receptor and causing the cytotoxicity of B cell lymphocytes, which results in halting the immune response mediated through this pathway. The standard dose is given to LEMS patients at $375 \mathrm{mg} / \mathrm{m}^{2}$ once weekly for four weeks and then every month for the next two months [40]. The side effects associated with rituximab include cardiac disorders, such as arrhythmias and acute coronary syndrome, and in other systems, anaphylaxis, allergic reactions, nausea, and vomiting [41].

\section{Plasma Exchange}

Patients suffering from the antibody-mediated disorder with a refractory pattern have multiple options, and plasma exchange has shown beneficial effects in them. In patients suffering from LEMS, it has limited advantages, but with concomitant use with another immunosuppressive disorder, it can be beneficial in some patients [42-43]. The recommended protocol for MG is five exchanges over the course of seven to 14 days but no recommendations have been made for LEMS. Therefore, it is suggested to use the same protocol in LEMS, as the pathology is the same between the two disorders [44]. 


\section{Cureus}

\section{Prognosis}

The major determinant of prognosis in LEMS has been the presence of neoplasm. In patients with SCLC associated with LEMS, longer survival has been observed as compared to patients with SCLC but no associated neurological illness [45]. In patients without any associated neoplasm, survival is normal or near-normal, as seen in a study; in 47 patients with LEMS without SCLC, 10 patients died at a mean age of 70 years unrelated to the LEMS. However, two deaths were possibly related to complications of glucocorticoid therapy [46].

Table 3 provides a list of take-home messages.

\section{Take-Home Messages}

Lambert-Eaton Myasthenic Syndrome is an autoimmune disorder of the neuromuscular junction.

Antibodies are formed against the Voltage-Gated Calcium Channels (VGCC) on presynaptic nerve terminals, thus inhibiting acetylcholine release.

The classic triad presents as muscle weakness, decreased tendon reflexes and autonomic dysfunction.

The investigative tools that can confirm clinical findings are nerve conduction studies, antibody profile, and electromyography.

The treatment options are primarily focused to improve the symptoms, primarily the weakness.

Amifampridine has been recently approved by the FDA for the symptomatic treatment of weakness and it's the base salt of 3,4-Diaminopyridine (3,4-DAP).

Other treatment options available include guanidine, pyridostigmine, intravenous immune globulin, immunosuppressive agents (Prednisone, Azathioprine, Cyclosporine, Mycophenolate), rituximab, plasma exchange.

\section{TABLE 3: Take-home messages}

\section{Conclusions}

LEMS is a rare autoimmune-mediated neuromuscular disorder caused by a decrease in acetylcholine release from the neuromuscular junction. The prognosis of LEMS depends upon the presence of malignancy, as it can shorten survival in these patients, but near-normal life expectancy has been observed in idiopathic LEMS. The treatment options are primarily focused on the symptomatic improvement of weakness, and these include amifampridine, guanidine, and pyridostigmine. For refractory weakness, patients can go for IVIG, prednisone, or other immunosuppressive agents. Rituximab and plasma exchange have also been proven to be beneficial in some refractory cases.

\section{Additional Information}

\section{Disclosures}

Conflicts of interest: In compliance with the ICMJE uniform disclosure form, all authors declare the following: Payment/services info: All authors have declared that no financial support was received from any organization for the submitted work. Financial relationships: All authors have declared that they have no financial relationships at present or within the 
previous three years with any organizations that might have an interest in the submitted work. Other relationships: All authors have declared that there are no other relationships or activities that could appear to have influenced the submitted work.

\section{References}

1. Lorenzoni PJ, Kay CS, Werneck LC, Scola RH: Lambert-Eaton myasthenic syndrome: the 60th anniversary of Eaton and Lambert's pioneering article [Article in English, Portuguese]. Arq Neuropsiquiatr. 2018, 76:124-126. 10.1590/0004-282x20170194

2. Lennon VA, Kryzer TJ, Griesmann GE, et al.: Calcium-channel antibodies in the LambertEaton syndrome and other paraneoplastic syndromes. N Engl J Med. 1995, 1:1467-1475. 10.1056/nejm199506013322203

3. Titulaer MJ, Wirtz PW, Kuks JB, et al.: The Lambert-Eaton myasthenic syndrome 1988-2008: a clinical picture in 97 patients. J Neuroimmunol. 2008, 15:153-158.

10.1016/j.jneuroim.2008.05.025

4. Jayarangaiah A, Kariyanna PT: Lambert Eaton Myasthenic Syndrome. InStatPearls, Treasure Island (FL), US; 2019.

5. Elrington GM, Murray NM, Spiro SG, Newsom-Davis J: Neurological paraneoplastic syndromes in patients with small cell lung cancer. A prospective survey of 150 patients. J Neurol Neurosurg Psychiatry. 1991, 54:764-767. 10.1136/jnnp.54.9.764

6. Gilhus NE: Lambert-Eaton myasthenic syndrome; pathogenesis, diagnosis, and therapy . Autoimmune Dis. 2011, 2011:973808. 10.4061/2011/973808

7. Motomura M, Johnston I, Lang B, Vincent A, Newsom-Davis J: An improved diagnostic assay for Lambert-Eaton myasthenic syndrome. J Neurol Neurosurg Psychiatry. 1995, 58:85-87. 10.1136/jnnp.58.1.85

8. Wirtz PW, Bradshaw J, Wintzen AR, Verschuuren JJ: Associated autoimmune diseases in patients with the Lambert-Eaton myasthenic syndrome and their families. J Neurol. 2004, 251:1255-1259. 10.1007/s00415-004-0528-7

9. Titulaer MJ, Verschuuren JJ: Lambert-Eaton myasthenic syndrome. Tumor versus nontumor forms. Ann N Y Acad Sci. 2008, 1132:129-134. 10.1196/annals.1405.030

10. Huelsbrink R, Hashemolhosseini S: Lambert-Eaton myasthenic syndrome - diagnosis, pathogenesis and therapy. Clin Neurophysiol. 2014, 125:2328-2336.

10.1016/j.clinph.2014.06.031

11. Titulaer MJ, Lang B, Verschuuren JJ: Lambert-Eaton myasthenic syndrome: from clinical characteristics to therapeutic strategies. Lancet Neurol. 2011, 10:1098-1107. 10.1016/s14744422(11)70245-9

12. Varma S: Electromyography and neuromuscular disorders: clinical-electrophysiologic correlations, 3rd Edition, edited by David C. Preston and Barbara E. Shapiro, 664 pp., Elsevier Saunders. Muscle Nerve. 2012, 48:308. 10.1002/mus.23894

13. Chiou-Tan FY, Tim RW, Gilchrist JM, et al.: Practice parameter for repetitive nerve stimulation and single fiber EMG evaluation of adults with suspected myasthenia gravis or Lambert-Eaton myasthenic syndrome: summary statement. Muscle Nerve. 2001, 1:1236-1238. 10.1002/mus.1139

14. Hatanaka Y, Oh SJ: Ten-second exercise is superior to 30-second exercise for post-exercise facilitation in diagnosing Lambert-Eaton myasthenic syndrome. Muscle Nerve. 2008, 37:572575. 10.1002/mus.20979

15. Pellkofer HL, Armbruster L, Krumbholz M, Titulaer MJ, Verschuuren JJ, Schumm F, Voltz R: Lambert-Eaton myasthenic syndrome differential reactivity of tumor versus non-tumor patients to subunits of the voltage-gated calcium channel. J Neuroimmunol. 2008, 204:136139. 10.1016/j.jneuroim.2008.08.002

16. Mason WP, Graus F, Lang B, et al.: Small-cell lung cancer, paraneoplastic cerebellar degeneration and the Lambert-Eaton myasthenic syndrome. Brain. 1997, 120:1279-300.

17. Wang S, Bruzzi J, Rodriguez-Garza VP, Komaki RR: Lambert-Eaton myasthenic syndrome in a patient with small-cell lung cancer. Clin Lung Cancer. 2006, 7:282-284.

10.3816/CLC.2006.n.008

18. Tarr TB, Wipf P, Meriney SD: Synaptic pathophysiology and treatment of Lambert-Eaton myasthenic syndrome. Mol Neurobiol. 2015, 52:456-463. 10.1007/s12035-014-8887-2

19. Wirtz PW, Verschuuren JJ, Van Dijk JG, et al.: Efficacy of 3, 4-diaminopyridine and 
pyridostigmine in the treatment of Lambert-Eaton myasthenic syndrome: a randomized, double-blind, placebo-controlled, crossover study. Clin Pharmacol Ther. 2009, 86:44-48. 10.1038/clpt.2009.35

20. Sanders DB, Juel VC, Harati Y, et al.: 3,4-diaminopyridine base effectively treats the weakness of Lambert-Eaton myasthenia. Muscle Nerve. 2018, 57:561-568. 10.1002/mus.26052

21. Kesner VG, Oh SJ, Dimachkie MM, Barohn RJ: Lambert-Eaton myasthenic syndrome. Neurol Clin. 2018, 36:379-394. 10.1016/j.ncl.2018.01.008

22. Raust JA, Goulay-Dufay S, Le Hoang MD, Pradeau D, Guyon F, Do B: Stability studies of ionised and non-ionised 3, 4-diaminopyridine: hypothesis of degradation pathways and chemical structure of degradation products. J Pharm Biomed Anal. 2007, 4:83-8.

10.1016/j.jpba.2006.06.007

23. U.S. Food \& Drug Administration. FDA approves first treatment for Lambert-Eaton myasthenic syndrome, a rare autoimmune disorder. (2018). https://www.fda.gov/newsevents/press-announcements/fda-approves-first-treatment-lambert-eaton-myasthenicsyndrome-ra....

24. Sanders DB, Massey JM, Sanders LL, Edwards LJ: A randomized trial of 3,4-diaminopyridine in Lambert-Eaton myasthenic syndrome. Neurology. 2000, 54:603. 10.1212/wnl.54.3.603

25. McEvoy KM, Windebank AJ, Daube JR, Low PA: 3,4-diaminopyridine in the treatment of Lambert-Eaton myasthenic syndrome. N Engl J Med. 1989, 7:1567-1571. 10.1056/NEJM198912073212303

26. Oh SJ, Shcherbakova N, Kostera-Pruszczyk A, et al.: Amifampridine phosphate (Firdapse ${ }^{\circledR}$ ) is effective and safe in a phase 3 clinical trial in LEMS. Muscle Nerve. 2016, 53:717-725. 10.1002/mus.25070

27. Oh SJ, Claussen GG, Hatanaka Y, Morgan MB: 3,4-diaminopyridine is more effective than placebo in a randomized, double-blind, cross-over drug study in LEMS. Muscle Nerve. 2009, 40:795-800. 10.1002/mus.21422

28. Keogh M, Sedehizadeh S, Maddison P: Treatment for Lambert-Eaton myasthenic syndrome. Cochrane Database Syst Rev. 2011, 2011:CD003279. 10.1002/14651858.CD003279.pub3

29. Sanders DB, Juel VC, Harati Y, et al.: 3,4-diaminopyridine base effectively treats the weakness of Lambert-Eaton myasthenia. Muscle Nerve. 2018, 57:561-568. 10.1002/mus.26052

30. Oh SJ, Kim DS, Head TC, Claussen GC: Low-dose guanidine and pyridostigmine: relatively safe and effective long-term symptomatic therapy in Lambert-Eaton myasthenic syndrome. Muscle Nerve. 1997, 20:1146-1152.

31. Kalia J, Swartz KJ: Elucidating the molecular basis of action of a classic drug: guanidine compounds as inhibitors of voltage-gated potassium channels. Mol Pharmacol. 2011, 80:10851095. 10.1124/mol.111.074989

32. Bayry J, Thirion M, Misra N, et al.: Mechanisms of action of intravenous immunoglobulin in autoimmune and inflammatory diseases. Neurol Sci. 2003, 24:217-221. 10.1007/s10072-0030081-7

33. Bain PG, Motomura M, Newsom-Davis J, et al.: Effects of intravenous immunoglobulin on muscle weakness and calcium-channel autoantibodies in the Lambert-Eaton myasthenic syndrome. Neurology. 1996, 47:678-683. 10.1212/wnl.47.3.678

34. Wittstock M, Benecke R, Zettl UK: Therapy with intravenous immunoglobulins: complications and side-effects. Eur Neurol. 2003, 50:172-175. 10.1159/000073059

35. Streib EW, Rothner AD: Eaton-Lambert myasthenic syndrome: long-term treatment of three patients with prednisone. Ann Neurol. 1981, 10:448-453. 10.1002/ana.410100507

36. Newsom-Davis J: Therapy in myasthenia gravis and Lambert-Eaton myasthenic syndrome . Semin Neurol. 2003, 23:191-198. 10.1055/s-2003-41135

37. Sanders DB: Lambert-Eaton myasthenic syndrome: diagnosis and treatment. Ann N Y Acad Sci. 2003, 998:500-508. 10.1196/annals.1254.065

38. Maddison P, McConville J, Farrugia ME, et al.: The use of rituximab in myasthenia gravis and Lambert-Eaton myasthenic syndrome. J Neurol Neurosurg Psychiatry. 2011, 82:671-673.

10.1136/jnnp.2009.197632

39. Boutin E, Rey C, Romeu M, Pouget J, Franques J: Favourable outcome after treatment with rituximab in a case of seronegative non-paraneoplastic Lambert-Eaton myasthenic syndrome [Article in French, English]. Rev Med Interne. 2013, 34:493-496. 10.1016/j.revmed.2013.04.007

40. Weiner GJ: Rituximab: mechanism of action. Semin Hematol. 2010, 47:115-123. 


\section{Cureus}

\subsection{3/j.seminhematol.2010.01.011}

41. Diaz-Manera J, Martínez-Hernández E, Querol L, et al.: Long-lasting treatment effect of rituximab in MuSK myasthenia. Neurology. 2012, 17:189-193.

10.1212/WNL.0b013e3182407982

42. Dau PC, Denys EH: Plasmapheresis and immunosuppressive drug therapy in the EatonLambert syndrome. Ann Neurol. 1982, 11:570-575. 10.1002/ana.410110604

43. Motomura M, Hamasaki S, Nakane S, Fukuda T, Nakao YK: Apheresis treatment in LambertEaton myasthenic syndrome. Ther Apher. 2000, 1:287-290. 10.1046/j.15260968.2000.004004287.x

44. Newsom-Davis J, Murray NM: Plasma exchange and immunosuppressive drug treatment in the Lambert-Eaton myasthenic syndrome. Neurology. 1984, 34:480. 10.1212/wnl.34.4.480

45. Maddison P, Gozzard P, Grainge MJ, Lang B: Long-term survival in paraneoplastic LambertEaton myasthenic syndrome. Neurology. 2017, 88:1334-1339.

46. Maddison P, Lang B, Mills K: Long term outcome in Lambert-Eaton myasthenic syndrome without lung cancer. J Neurol Neurosurg Psychiatry. 2001, 70:212-217. 10.1136/jnnp.70.2.212 